\title{
Risk management in Iraqi Oil Field Kurdistan Regional Government Case study (Upstream)
}

\author{
Kanaan M. Abdlkareem Alhiti ${ }^{1, \mathrm{a}}$ and Amjed Abdulqadir Mohammed ${ }^{1, \mathrm{~b}}$ \\ ${ }^{1}$ AL-Farabi University College, Baghdad, Iraq. \\ akananalhiti@yahoo.com, bamjed1953@yahoo.co.uk
}

\begin{abstract}
The investment decision-maker in oil exploration projects faces overlap in the main criteria, sub-criteria, and attributes of the reasons that control the investment decision, which requires a mechanism that identifies and measures risks in terms of quantity and quality for all alternatives under study. Having a mechanism that deals with such cases will help the decision-maker choose the best alternative by measuring risks and giving the best solution. The main objective of this study is to transfer the uncertainty resulting from the difference in the criteria and features of the problem under investigation into a mechanism that integrates both the Analytical Hierarchy Process (AHP) with the Technique for Order Preference by Similarity to Ideal Solution (TOPSIS) to choose the optimal solution. The researchers used each (TOPSIS) and APH combined with choosing alternatives by defining criteria, sub-criteria, and oil exploration attributes. Risk management in oil exploration in the Kurdistan region was the subject of this research, which concluded that Erbil blocks' investment is better than the rest of the region. This methodology will act as a guide to help the decision-maker find the best alternative by using both techniques in finding the best investment decision.
\end{abstract}

Keywords: AHP method; TOPSIS method; DM; risk management.

\section{Introduction}

The activities and works represented by oil exploration, foremost of which are drillings, are the cornerstone for finding and extracting oil. Iraq possesses one of the world's largest oil reserves and is one of the early founders of the Organization of Petroleum Exporting Countries. Iraqi Kurdistan is a region with wide powers and is recognized federally in Iraq. The three provinces of Duhok, Erbil, and Suleimaniah form the Kurdistan Region covering an area of approximately 40000 square kilometers. Exploration is the process of finding oil in the ground and determining its quantity, consistency, and current reservoir conditions such as temperature, pressure, porosity, and permeability, and preparing the field for production and growth. The exploration process starts with reviewing all available information for the exploration field, including geological structure, installed faults, cracks, and other geological phenomena that affect oil formation, emigration, or absence. Figure 1 shows Kurdistan Regional Government upstream Block.

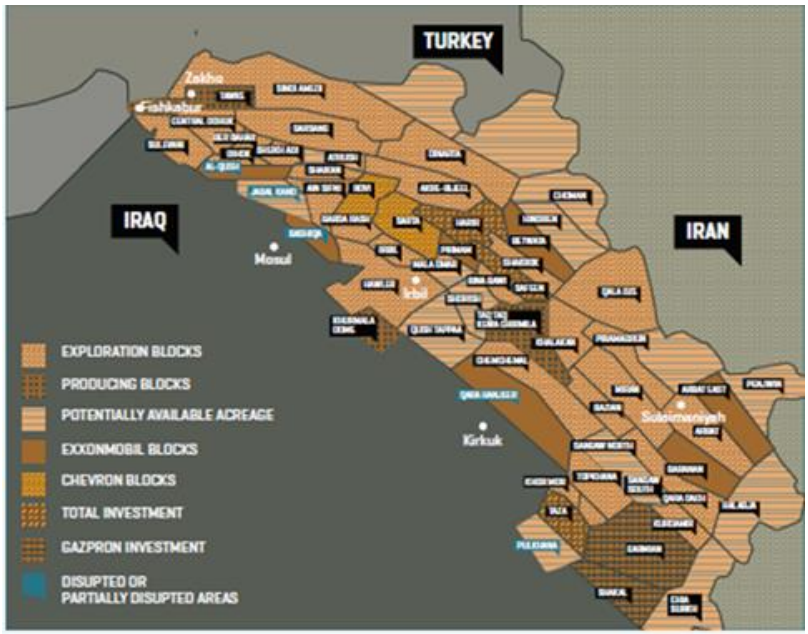

Figure 1. Kurdistan Regional Government upstream block.

Source: (CMiddle East Petroleum and Economic Publications (Cyprus) Ltd 09, November, 2012. 
Effective risk management is an integral part of any successful management plan. Risk management is a systematic and thorough approach to defining, assessing, and reacting to threats in order to meet project goals. Among the decision-making process's primary duties is to derive the best choice among the alternatives under consideration. The system of multiple attribute decision-making (MADM) is used to evaluate financial results. (Ramanathan and Ganesh, [1]) (MADM) is the process of selecting the best option from a finite set of decision alternatives based on several, often conflicting attributes. The attributes are essential in the decision-making process. Simple additive weighting is (SAW) one of the most popular MADM methodologies [2]. The technique for order preference by similarity to ideal solution (TOPSIS) [3], analytical hierarchy process (AHP) [4], data envelopment analysis (DEA) [5]. However, there's no guarantee that these two types of preference relations will result in the same estimation of relative attribute weights [6].

Wang [7] applied the fuzzy TOPSIS method to assess airline financial results and use grey relation analysis to find representative metrics from financial ratios. Emel [8] used rough-AHP and fuzzy TOPSIS to analyze four Turkish aviation firms' performance, and we devised a complete method in collaboration with the company to assess their performance indicators and weights in the total score. The analytic hierarchy processes method (AHP) is a multi-criteria decision-making mechanism for organizing and evaluating complex decisions developed first [4]. In various research domains, the AHP approach has been adopted as a reliable and versatile multi-criteria decision-making tool for dealing with complex decision problems [9]. The AHP is a method for determining acceptable weights using expert judgments. This paper develops a systematic approach in order to combine AHP with TOPSIS when the input linguistic and crisp numbers. In the next section, the authors presented the methodology of AHP and TOPSIS. In section four a case study for ranking alternative in the field of oil exploration on Iraq Kurdistan regional. Finally, concluding remarks are provided.

\section{Research Methodology}

The first step in dealing with multiple criteria decision-making (MCDM) with problems of multiple criteria and attributes is to determine the number of these criteria and the attributes present in the problem and define them (i.e., identifying the problems). Following that, information and data are gathered in a detailed and reasonable manner so that DM's interests can be adequately reflected on and considered (i.e., constructing the preferences). Prepare a list of options and strategies to ensure that the desired objectives are met (i.e., evaluating the alternatives). Finally, deciding the best strategy for testing alternatives or methods and organizing or strengthening them (i.e., finding and determining the best alternative). In this paper, the researchers use AHP and TOPSIS methods to deals with risk management in the oil field (exploration stage). To extract relative weights according to the required hierarchical system, the analytic hierarchy method (AHP) was suggested. Four methods are proposed to obtain the weights using the AHP: the eigenvalue method, the geometric mean method, the linear programming method, and the lambda-max method [10]. The AHP's four key stages are outlined as follows:

Step 1: Create a hierarchy of interconnected elements to analyze the problem.

Step 2: Construct the reciprocal matrix by comparing the relative weights of the decision elements' criteria. Matrix developed for pairwise comparison based on respondents' judgment as stated in Eq. 1:

$$
\mathrm{C}=\left[\begin{array}{cccc}
1 & \frac{\mathrm{w}_{1}}{\mathrm{w}_{2}} & \cdots & \frac{\mathrm{w}_{1}}{\mathrm{w}_{\mathrm{n}}} \\
\frac{\mathrm{w}_{2}}{\mathrm{w}_{1}} & 1 & \cdots & \frac{\mathrm{w}_{2}}{\mathrm{w}_{\mathrm{n}}} \\
\vdots & \vdots & \ddots & \vdots \\
\frac{\mathrm{w}_{\mathrm{n}}}{\mathrm{w}_{1}} & \frac{\mathrm{w}_{\mathrm{n}}}{\mathrm{w}_{2}} & \cdots & 1
\end{array}\right]=\left[\begin{array}{cccc}
\mathrm{a}_{11} & \mathrm{a}_{12} & \cdots & \mathrm{a}_{1 \mathrm{n}} \\
\mathrm{a}_{21} & \mathrm{a}_{22} & \cdots & \mathrm{a}_{2 \mathrm{n}} \\
\vdots & \vdots & \ddots & \vdots \\
\mathrm{a}_{\mathrm{n} 1} & \mathrm{a}_{\mathrm{n} 2} & \cdots & \mathrm{a}_{\mathrm{nn}}
\end{array}\right]
$$

Where $\mathrm{C}$ is the matrix with the pairwise matrix's $a_{i j}$ unit in the $i$ column and $j$ row and the rated weight of factors $w=\left(w_{1}, w_{2}, \ldots, w_{n}\right)$, where $(i, j=1,2, \ldots, n)$ and $n$ is the number of factors. 
Step 3: Summarize each individual's subjective opinion and calculate the relative weight;

$\mathrm{W}_{\mathrm{i}}=\frac{\mathrm{w}_{\mathrm{i}}}{\sum_{\mathrm{i}=1}^{\mathrm{n}} \mathrm{w}_{\mathrm{i}}}$ but $\mathrm{w}_{\mathrm{i}}=\sum_{\mathrm{j}=1}^{\mathrm{n}} \mathrm{a}_{\mathrm{ij}} \quad(\mathrm{i}=1,2, \ldots \ldots \ldots, \mathrm{n})$

Where $\mathrm{W}_{\mathrm{i}}$ is the normalized weight derived from the overall weight $\mathrm{W}=\left(\mathrm{w}_{1}, \mathrm{w}_{2}, \ldots, \mathrm{W}_{\mathrm{n}}\right)$. The consistency ratio can be used to define decision consistency. Determine the consistency ratio by first computing the random indexing (RI) and consistency index (CI) and (CR). Finally, the decision is consistent if $\mathrm{CR}$ is greater than or equal to zero and less than or equal to 0.1 [11]. The relations for the checking consistency can be expressed as Eq. 3:

$\mathrm{CR}=\frac{\mathrm{CI}}{\mathrm{RI}}$ but $\mathrm{CI}=\frac{\lambda \max -\mathrm{n}}{\mathrm{n}-1}$ Where; $\lambda_{\max }=\sum_{\mathrm{i}}^{\mathrm{n}} \mathrm{a}_{i j} \times \mathrm{w}_{i}$

Step 4: Add up the various elements' relative weights to find the best options/strategies.

$\begin{aligned} & \mathrm{r}_{\mathrm{ik}}=\frac{\mathrm{r}_{\mathrm{i}}}{\mathrm{N}} \text { then } \mathrm{R}=\left[\begin{array}{ccccc}\mathrm{r}_{11} & \mathrm{r}_{12} & \mathrm{r}_{13} & \mathrm{a}_{14} & \mathrm{r}_{15} \\ \mathrm{r}_{21} & \mathrm{r}_{22} & \mathrm{r}_{23} & \mathrm{a}_{24} & \mathrm{a}_{25} \\ \vdots & \vdots & \vdots & \vdots & \vdots \\ \mathrm{r}_{\mathrm{n} 1} & \mathrm{r}_{\mathrm{n} 2} & \mathrm{r}_{\mathrm{n} 3} & \mathrm{a}_{\mathrm{n} 4} & \mathrm{r}_{\mathrm{n} 5}\end{array}\right] \\ & \mathrm{B}_{i}=W_{i} \times R_{i}=\left[\begin{array}{l}\mathrm{W}_{1} \\ \mathrm{~W}_{2} \\ \mathrm{~W}_{3} \\ \mathrm{~W}_{4}\end{array}\right] \times\left[\begin{array}{ccccc}\mathrm{r}_{11} & \mathrm{r}_{12} & \mathrm{r}_{13} & \mathrm{a}_{14} & \mathrm{r}_{15} \\ \mathrm{r}_{21} & \mathrm{r}_{22} & \mathrm{r}_{23} & \mathrm{a}_{24} & \mathrm{a}_{25} \\ \vdots & \vdots & \vdots & \vdots & \vdots \\ \mathrm{r}_{\mathrm{n} 1} & \mathrm{r}_{\mathrm{n} 2} & \mathrm{r}_{\mathrm{n} 3} & \mathrm{a}_{\mathrm{n} 4} & \mathrm{r}_{\mathrm{n} 5}\end{array}\right]=\left[\begin{array}{lllll}\mathrm{b}_{\mathrm{i} 1} & \mathrm{~b}_{\mathrm{i} 2} & \mathrm{~b}_{\mathrm{i} 3} & \mathrm{~b}_{\mathrm{i} 4} & \mathrm{~b}_{\mathrm{i} 5}\end{array}\right]\end{aligned}$

\section{Technique for Order Preference by Similarity to Ideal Solution (TOPSIS)}

In TOPSIS techniques, the best and worst alternatives are searched. According to this technique, the alternative that has the shortest distance from the positive ideal solution and the farthest distance from the negative ideal solution is the perfect alternative [12].

Step (1) prepare normalized decision matrix. The importance of this matrix comes from the fact that the factors composing it have a different rated value, and if there is more than one value for the factor, the average of these values represents the value of that factor, according to which it can be compared, the matrix computed using Eq. 6:

$\mathrm{u}_{\mathrm{ij}}=\frac{\mathrm{a}_{\mathrm{ij}}}{\sqrt{\sum_{\mathrm{i}=1}^{\mathrm{n}} \mathrm{a}_{i j}^{2}}} \quad \mathrm{i}=1,2,4, \ldots, \mathrm{j}=1,2, \ldots, \ldots, \ldots$,

Where $\mathrm{u}_{\mathrm{ij}}$ is a normalized decision matrix, $\mathrm{a}_{\mathrm{ij}}$ is the rated value of alternatives.

Step (2) estimates the weighted normalized decision matrix. Based on the expression, the weighted normalized decision matrix $\mathrm{V}_{\mathrm{ij}}$ was computed as Eq. 7:

$\mathrm{V}_{\mathrm{ij}}=W_{i} \times \mathrm{u}_{\mathrm{ij}} \quad \mathrm{i}=1,2,3, \ldots, \mathrm{n} . \quad \mathrm{j}=1,2,3, \ldots, \mathrm{n}$.

Where $\mathrm{w}_{\mathrm{i}}$ is the normalized weight of $\mathrm{i}$ th factors and $\mathrm{u}_{\mathrm{ij}}$ is normalized decision matrix.

Step (3) Identify the positive ideal solution (PIS) \& the negative ideal solution (NIS). The (PIS) and (NIS) can be determined from a weighted normalize decision matrix using Eqs. 8 and 9.

$\mathrm{A}^{*}=\left\{\mathrm{V}_{1}^{*}, \mathrm{~V}_{2}^{*}, \mathrm{~V}_{3}^{*}, \ldots \ldots, \mathrm{V}_{\mathrm{n}}^{*}\right\}$ maximum values, where $\left\{\mathrm{V}_{\mathrm{i}}^{*} \max \left(\mathrm{V}_{\mathrm{ij}}\right.\right.$ if $\left.\mathrm{j} \in \mathrm{J}\right\}$

$A^{-}=\left\{V_{1}^{-}, V_{2}^{-}, V_{3}^{-}, \ldots \ldots, V_{n}^{-}\right\}$maximum values, where $\left\{V_{i}^{-} \max \left(V_{i j}\right.\right.$ if $\left.j \in J\right\}$

Step (4) calculate the Euclidean distance of the alternatives. The (PIS) and (NIS) represented by $\mathrm{d}_{\mathrm{i}}^{*}$ and $\mathrm{d}_{\mathrm{i}}^{-}$respectively using Eqs. 10 and 11:

$$
d_{i}^{*}=\sqrt{\sum_{j=1}^{n}\left(V_{i j}-V \times j\right)^{2}} \quad i=1,2,3, \ldots, n . \quad j=1,2,3, \ldots, n
$$




$$
\mathrm{d}_{\mathrm{i}}^{-}=\sqrt{\sum_{\mathrm{j}=1}^{\mathrm{n}}\left(\mathrm{V}_{\mathrm{ij}}-\overline{\mathrm{V}}_{j}\right)^{2}} \quad \mathrm{i}=1,2,3, \ldots, \mathrm{n} . \quad \mathrm{j}=1,2,3, \ldots, \mathrm{n}
$$

Step (5) computes the relative Closeness Coefficient to the ideal solution for the alternatives under study using Eq. 12.

$$
\mathrm{CC}_{\mathrm{i}} \frac{\mathrm{d}_{\mathrm{i}}^{-}}{\mathrm{d}_{\mathrm{i}}^{*}+\mathrm{d}_{\mathrm{i}}^{-}} \quad \mathrm{i}=1,2,3, \ldots, \mathrm{n} . \quad \mathrm{j}=1,2,3, \ldots, \mathrm{n}
$$

Finally, alternatives are rated from most valuable to least valuable based on declining Closeness Coefficient values. The greatest Closeness Coefficient values are chosen.

\section{Case Study}

Based on the literature review and the open interviews with specialists in the field of oil exploration, the research team prepared a preliminary questionnaire to determine the main criteria, sub-criteria, and attributes that govern the risks of managing the investment in the exploration stage in the Kurdistan region. The questionnaire was presented in its final form, and the results were elaborated according to Tables 1 to 3; the research team selected five experts in the field of oil exploration along with two academics to advise as in Table 4. AHP method is used to measure the weight of key criteria and sub-criteria based on the decision makers' subjective judgments. The following is a pairwise comparison matrix of the key parameters (Table 5) as well as the weights measurement. Equation 1 has been used to measure the normalized matrix-C. The priority weights are computed using Eq. 2. Equation 4 is used to measure the elements of the eigenvector. The weight of main criteria was $(0.26,0.56,0.12,0.06)$. To calculate $\lambda_{\max }$ :

Consistency Index $(\mathrm{CI})=$ Consistency Index $(\mathrm{CI})=\frac{\lambda_{\max }-n}{n-1}=\frac{4.1234-4}{3}=0.0411$

Consistency Ratio $=\mathrm{CI} / \mathrm{RI}, \mathrm{RI}=0.9, \mathrm{CR}=0.0411 / 0.9=0.0456<0.1$ is O.K. The same procedure done to sub criteria Table (6). The TOPSIS method for (attribute) calculated as in Table (7).

\begin{tabular}{|c|c|c|}
\hline Criteria & $\begin{array}{c}\text { Sub } \\
\text { Criteria }\end{array}$ & Attribute Related \\
\hline \multirow{17}{*}{ 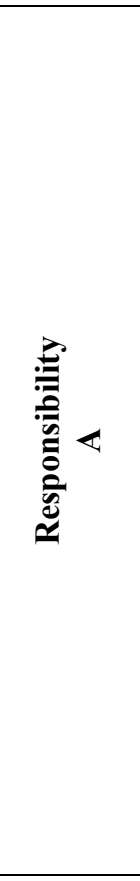 } & \multirow{8}{*}{ 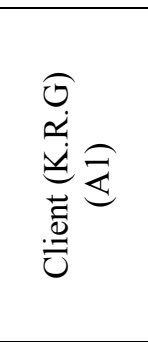 } & Payments aren't made in time, so finance (A11) \\
\hline & & Client interference (A12) \\
\hline & & Explore may not get insurance for drilling rig. (A13) \\
\hline & & The site for design and drilling not delivered on time (A14) \\
\hline & & Inadequate geological information's (A15) \\
\hline & & Communication and coordination with other are inadequate (A16) \\
\hline & & Subcontractors' problems (A17) \\
\hline & & Poor site performance and management (A18) \\
\hline & \multirow{4}{*}{ 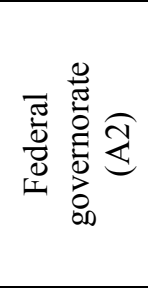 } & Disputes between Federal governorate and KG (A21) \\
\hline & & Failure to legislate oil and gas law at the federal level (A22) \\
\hline & & $\begin{array}{l}\text { The federal government pressured international companies to prevent them from } \\
\text { contracting with the Kurdistan government and to consider contracting illegal } \\
\text { (A23) }\end{array}$ \\
\hline & & $\begin{array}{l}\text { The effect of the federal government on the Turkish government and its impact } \\
\text { on the export of extracted oil (A24) }\end{array}$ \\
\hline & \multirow{5}{*}{ 密 } & Improper drilling machines (A31) \\
\hline & & Poor coordination and communication with other (A32) \\
\hline & & $\begin{array}{l}\text { Inadequate experience of the Contractor and Major companies are prohibited } \\
\text { from working within the region (A33) }\end{array}$ \\
\hline & & Rework for unsatisfactory work (A34) \\
\hline & & Inadequate consultant experience (A35) \\
\hline
\end{tabular}

Table 1. Responsibility (A) and sub-criteria attribute for exploration. 
Table 2. Resources (B) and sub-criteria attribute for exploration.

\begin{tabular}{|c|c|c|}
\hline Criteria & Sub-Criteria & Attribute Related \\
\hline \multirow{40}{*}{ 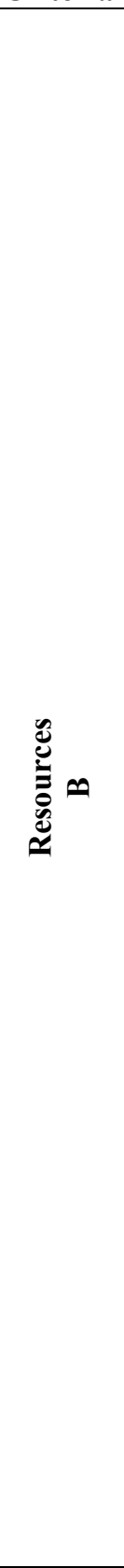 } & \multirow{5}{*}{ API degree (B1) } & Heavy oil (B11) \\
\hline & & Medium oil (B12) \\
\hline & & Light oil (B13) \\
\hline & & Super light oil (B14) \\
\hline & & Gas (B15) \\
\hline & \multirow{2}{*}{ No. of reservoir (B2) } & Single reservoir (B21) \\
\hline & & Multi-reservoir (B22) \\
\hline & \multirow{2}{*}{ Seismic data (B3) } & 2D seismic+ Exploration Well (B31) \\
\hline & & 3D Seismic (B32) \\
\hline & \multirow{5}{*}{ GOR (B4) } & $\geq 300 \mathrm{scf} / \mathrm{bbl}(\mathrm{B} 41)$ \\
\hline & & $\geq 100.000 \mathrm{scf} / \mathrm{bbl}(\mathrm{B} 42)$ \\
\hline & & $\leq 1.000 .000 \mathrm{scf} / \mathrm{bbl}(\mathrm{B} 43)$ \\
\hline & & $>1.000 .000 \mathrm{scf} / \mathrm{bbl}(\mathrm{B} 44)$ \\
\hline & & Coal bed Methane (B45) \\
\hline & \multirow{5}{*}{$\begin{array}{l}\text { Depth of reservoirs } \\
\text { (B5) }\end{array}$} & Tertiary reservoirs (B51) \\
\hline & & Cretaceous reservoirs (B52) \\
\hline & & Jurassic reservoirs (B53) \\
\hline & & Triassic reservoirs (B54) \\
\hline & & Paleozoic reservoirs (B55) \\
\hline & \multirow{4}{*}{ Total reserve (B6) } & Small field (B61) \\
\hline & & Medium field (B62) \\
\hline & & Giant field (B63) \\
\hline & & Super Giant field (B64) \\
\hline & \multirow{3}{*}{$\begin{array}{c}\text { Reservoir } \\
\text { characteristics (B7) }\end{array}$} & Structure of reservoir (B71) \\
\hline & & Homogeneity (B72) \\
\hline & & Petrophysical properties (B73) \\
\hline & \multirow{4}{*}{ Finance (B8) } & Issues with a financial argument (B81) \\
\hline & & Government funding processes problems (B82) \\
\hline & & Delay of government budget release (B83) \\
\hline & & Financial crisis on a global scale (B84) \\
\hline & \multirow{5}{*}{ Labor (B9) } & Less productivity (B91) \\
\hline & & Low morale and motivation (B92) \\
\hline & & Unqualified workers (B93) \\
\hline & & Issues of discipline (conflicts) (B94) \\
\hline & & Labors safety problems (B95) \\
\hline & \multirow{5}{*}{ Equipment (B10) } & Insufficient or equipment shortage (B121) \\
\hline & & Poor equipment's performance and productivity (B122) \\
\hline & & Equipment breakdown and a shortage of spare parts (B123) \\
\hline & & Allocation \&mobilization Issues (B124) \\
\hline & & Useful life of the equipment is finished (B125) \\
\hline
\end{tabular}

Table 3. Contract condition (C), External (D), and sub-criteria attribute for exploration.

\begin{tabular}{|c|c|l|}
\hline Criteria & Sub-Criteria & \multicolumn{1}{c|}{ Attribute Related } \\
\hline & & Area awarded is set under each contract (C11) \\
\cline { 2 - 3 } & & Duration: The initial exploration period is five years, with the option to extend it up \\
to seven years. The five - year's term is split into two: three years and two- years \\
sub-periods (C12)
\end{tabular}




\begin{tabular}{|c|c|c|}
\hline & & $\begin{array}{l}\text { Cost Recovery: Cost recovery from a portion of production after deduction of the } \\
\text { Royalty, should not exceed forty-five percent ( } 45 \%) \text { for crude oil; and sixty percent } \\
(60 \%) \text { for natural gas (C16) }\end{array}$ \\
\hline & & $\begin{array}{l}\text { Profit Oil: Calculating the "R" Factor determines the percentage share of profit } \\
\text { Crude Oil and/or Profit Natural Gas to which the contractor is entitled. The R factor } \\
\text { is applied to each developed area separately (C17) }\end{array}$ \\
\hline & & $\begin{array}{l}\text { Rental: The contractor has to pay } 10 \text { USD per square } \mathrm{km} \text { as an annual surface rental } \\
\text { during the exploration period (C18) }\end{array}$ \\
\hline & & Taxation: Corporate income tax rate should not exceed $40 \%(\mathrm{C} 19)$ \\
\hline & & Deductions and Depreciation: (C20) \\
\hline & & The contract documents do not contain enough information (C21) \\
\hline \multirow{10}{*}{$\begin{array}{l}\text { External } \\
\text { (D) }\end{array}$} & \multirow{6}{*}{ 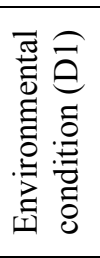 } & Adverse weather condition (D11) \\
\hline & & The force of majeure (D12) \\
\hline & & Corruption (D13) \\
\hline & & Cultural and social factors effect (D14) \\
\hline & & Commitment \& policy of KG (D15) \\
\hline & & Lack of utilities in a site (D16) \\
\hline & \multirow{4}{*}{ 总 $\widehat{\varrho}$} & Distance of field from the pipeline (D21) \\
\hline & & No. of pump stations (D22) \\
\hline & & API of oil (D23) \\
\hline & & The presence of the gas pipeline (D24) \\
\hline
\end{tabular}

Table 4. Expert's information.

\begin{tabular}{|c|c|c|c|c|}
\hline Role & No. & Educational qualifications & Experience (yrs) & Sector of work \\
\hline Consultant engineer & 1 & B.Sc. & 27 & Oil field/SOMO \\
\hline Consultant engineer & 2 & B.Sc. & 33 & Oil field /I.D.C \\
\hline General manager & 1 & M.Sc. & 22 & Oil field /N.R.C \\
\hline Consultant engineer & 1 & B.Sc. & 25 & Oil field /N.R.C \\
\hline Academic & 2 & Ph.D. & 35 & University \\
\hline
\end{tabular}

Table 5. Criteria pairwise comparison matrix.

\begin{tabular}{|c|c|c|c|c|}
\hline Criteria & Responsibility, A & Resources, B & Contract condition, C & External, D \\
\hline A & 1 & 0.3333 & 3 & 5 \\
\hline B & 3 & 1 & 5 & 7 \\
\hline C & 0.3333 & 0.2 & 1 & 3 \\
\hline D & 0.2 & 0.1429 & 0.3333 & 1 \\
\hline Summation & $\sum 4.5333$ & 1.6762 & 9.3333 & 16 \\
\hline
\end{tabular}

Table 6. Sub criteria weight.

\begin{tabular}{|c|c|c|c|c|c|c|c|c|c|c|c|c|c|c|c|c|}
\hline Sub criteria & A1 & A2 & A3 & B1 & B2 & B3 & B4 & B5 & B6 & B7 & B8 & B9 & B10 & C1 & D1 & D2 \\
\hline Sc. $\mathbf{w}$ & .03 & .02 & .04 & .05 & .06 & .04 & .07 & .05 & .02 & .07 & .10 & .04 & .04 & .08 & .05 & .05 \\
\hline
\end{tabular}

Table 7. Calculation steps of the TOPSIS method for attribute.

\begin{tabular}{|c|c|c|c|c|c|c|c|}
\hline Coefficient & DU & SUL & ERBIL & Coefficient & DU & SUL & ERBIL \\
\hline a11 & 0.18546 & 0.18735 & 0.21178 & B72 & 0.36164 & 0.36533 & 0.33802 \\
\hline a12 & 0.22658 & 0.22889 & 0.27661 & B73 & 0.49223 & 0.49725 & 0.46008 \\
\hline A13 & 0.16647 & 0.22889 & 0.21178 & B 81 & 0.67353 & 0.68040 & 0.62954 \\
\hline A14 & 0.22658 & 0.16817 & 0.21178 & B 82 & 0.67353 & 0.68040 & 0.62954 \\
\hline A15 & 0.29595 & 0.29896 & 0.27661 & B 83 & 0.85244 & 0.86113 & 0.79676 \\
\hline A16 & 0.22658 & 0.29896 & 0.27661 & B84 & 0.85244 & 0.86113 & 0.79676 \\
\hline A17 & 0.37456 & 0.37838 & 0.21178 & B91 & 0.46879 & 0.34793 & 0.57231 \\
\hline A18 & 0.22658 & 0.16817 & 0.21178 & B92 & 0.23918 & 0.24162 & 0.22356 \\
\hline A21 & 0.37456 & 0.37838 & 0.35009 & B93 & 0.46879 & 0.47357 & 0.43817 \\
\hline A22 & 0.29595 & 0.29896 & 0.27661 & B94 & 0.34442 & 0.34793 & 0.32192 \\
\hline A23 & 0.29595 & 0.29896 & 0.27661 & B95 & 0.23918 & 0.24162 & 0.22356 \\
\hline A24 & 0.37456 & 0.37838 & 0.35009 & B121 & 0.34442 & 0.34793 & 0.32192 \\
\hline A31 & 0.23440 & 0.17397 & 0.21909 & B122 & 0.34442 & 0.34793 & 0.32192 \\
\hline
\end{tabular}




\begin{tabular}{|c|c|c|c|c|c|c|c|}
\hline A32 & 0.23440 & 0.30927 & 0.28615 & B123 & 0.23918 & 0.24162 & 0.22356 \\
\hline A33 & 0.23440 & 0.30927 & 0.28615 & B124 & 0.23918 & 0.24162 & 0.22356 \\
\hline A34 & 0.30615 & 0.23679 & 0.28615 & B125 & 0.46879 & 0.47357 & 0.43817 \\
\hline A35 & 0.23440 & 0.23679 & 0.28615 & C11 & 0.20410 & 0.20618 & 0.19077 \\
\hline B11 & 0.78786 & 0.62886 & 0.73640 & C12 & 0.20410 & 0.20618 & 0.19077 \\
\hline B12 & 0.78786 & 0.62886 & 0.73640 & C13 & 0.15626 & 0.15786 & 0.14606 \\
\hline B13 & 0.47661 & 0.48147 & 0.73640 & C14 & 0.15626 & 0.15786 & 0.14606 \\
\hline B14 & 0.35016 & 0.35373 & 0.73640 & C15 & 0.07973 & 0.08054 & 0.07452 \\
\hline B15 & 0.24317 & 0.79590 & 0.32729 & C16 & 0.20410 & 0.20618 & 0.19077 \\
\hline B21 & 0.48442 & 0.48936 & 0.74847 & C17 & 0.25832 & 0.26095 & 0.24144 \\
\hline B22 & 0.48442 & 0.48936 & 0.74847 & C18 & 0.07973 & 0.08054 & 0.07452 \\
\hline B31 & 0.34442 & 0.34793 & 0.57231 & C19 & 0.25832 & 0.26095 & 0.24144 \\
\hline B32 & 0.34442 & 0.24162 & 0.57231 & C20 & 0.11481 & 0.11598 & 0.10731 \\
\hline B41 & 0.36164 & 0.25370 & 0.60092 & C21 & 0.25832 & 0.26095 & 0.24144 \\
\hline B42 & 0.36164 & 0.25370 & 0.60092 & D11 & 0.04385 & 0.04430 & 0.04099 \\
\hline B43 & 0.36164 & 0.25370 & 0.46008 & D12 & 0.04385 & 0.04430 & 0.04099 \\
\hline B44 & 0.36164 & 0.36533 & 0.60092 & D13 & 0.14207 & 0.14352 & 0.13279 \\
\hline B45 & 0.49223 & 0.64947 & 0.23473 & D14 & 0.06314 & 0.06379 & 0.05902 \\
\hline B51 & 0.35016 & 0.24565 & 0.73640 & D15 & 0.11226 & 0.11340 & 0.10492 \\
\hline B52 & 0.47661 & 0.35373 & 0.73640 & D16 & 0.08595 & 0.08682 & 0.08033 \\
\hline B53 & 0.35016 & 0.35373 & 0.58184 & D21 & 0.14207 & 0.14352 & 0.13279 \\
\hline B54 & 0.24317 & 0.24565 & 0.44547 & D22 & 0.14207 & 0.14352 & 0.13279 \\
\hline B55 & 0.47661 & 0.48147 & 0.73640 & D23 & 0.08595 & 0.08682 & 0.08033 \\
\hline B61 & 0.46098 & 0.46568 & 0.43087 & D24 & 0.06314 & 0.06379 & 0.05902 \\
\hline B62 & 0.46098 & 0.46568 & 0.56277 & d + & 7.76363 & 7.82309 & 7.49378 \\
\hline B63 & 0.46098 & 0.46568 & 0.56277 & d- & 2.83969 & 2.78756 & 3.34418 \\
\hline B64 & 0.60210 & 0.46568 & 0.71225 & cc & 0.57671 & 0.55358 & 0.80590 \\
\hline B71 & 0.49223 & 0.25370 & 0.46008 & - & - & - & - \\
\hline
\end{tabular}

\section{Conclusions}

Based on values of Closeness Coefficients, the study showed that investing in investment blocks in Erbil is the best alternative in Duhok, then Sulaymaniyah $(0.806,0.577$, and 0.554) depending on the resources of Erbil blocks (Near the conveyor line, the API degree, No. of the reservoir, GOR, Depth of reservoirs, and total reservoirs). The same technique can be used on exploration blocks within the same governorate to indicate which ones are the least risk.

\section{Reference}

[1] Ramanathan, R. and Ganesh, L.S., 1994. Group preference aggregation methods employed in AHP: An evaluation and an intrinsic process for deriving members' weightages. European journal of operational research, 79(2), pp.249-265.

[2] Andrasiu, M., Baciu, A., Pascu, A., Puscas, E. and Tasnadi, A., 1986. Metode de decizii multicriteriale, Bucuresti: Ed.

[3] Tzeng, G.H. and Huang, J.J., 2011. Multiple attribute decision making: methods and applications. CRC press.

[4] Saaty, T.L., 2014. Analytic heirarchy process. Wiley statsRef: Statistics reference online.

[5] Sinuany-Stern, Z., Mehrez, A. and Hadad, Y., 2000. An AHP/DEA methodology for ranking decision making units. International Transactions in Operational Research, 7(2), pp.109-124.

[6] Cheng, C.H., Chen, C.T. and Huang, S.F., 2012. Combining fuzzy integral with order weight average (OWA) method for evaluating financial performance in the semiconductor industry. African journal of business management, 6(21), pp.6358-6368.

[7] Wang, Y.J., 2008. Applying FMCDM to evaluate financial performance of domestic airlines in Taiwan. Expert Systems with Applications, 34(3), pp.1837-1845. 
[8] Aydogan, E.K., 2011. Performance measurement model for Turkish aviation firms using the rough-AHP and TOPSIS methods under fuzzy environment. Expert Systems with Applications, 38(4), pp.3992-3998.

[9] Boateng, P., Chen, Z. and Ogunlana, S.O., 2016. A dynamic framework for managing the complexities of risks in megaprojects. International journal of technology and management research, 1(5), pp.1-13.

[10]Tzeng, G.H. and Huang, J.J., 2011. Multiple attribute decision making: methods and applications. CRC press.

[11]Lee, M.C., 2014. Information security risk analysis methods and research trends: AHP and fuzzy comprehensive method. International Journal of Computer Science \& Information Technology, 6(1), p.29.

[12]Karim, R. and Karmaker, C.L., 2016. Machine selection by AHP and TOPSIS methods. American Journal of Industrial Engineering, 4(1), pp.7-13. 